\title{
Elemen-elemen Arsitektur Vernakular dalam Analisa Ruang dan Bentuk pada Gereja Pohsarang
}

\author{
Monica Basri \\ Jurusan Arsitektur, Tanri Abeng University \\ monicaervelinebasri@gmail.com
}

\begin{abstract}
Abstrak
Gereja adalah tempat suci bagi umat Katolik. Iman Katolik sendiri tidak berasal dari Nusantara, demikian pula arsitektur gereja Katolik tidak bergaya Nusantara. Hal tersebut menjadi alasan penelitian, yaitu untuk menganalisa bagaimana nilai lokal mempengaruhi bangunan keagamaan yang karakter aslinya sangat berbeda, dalam konteks ruang dan bentuk. Penelitian dilakukan dengan membandingkan tiga variabel yaitu: arsitektur, filosofi gereja, dan bangunan Jawa. Studi kasus yang digunakan adalah Gereja Pohsarang, yang terletak di Kota Kediri, Jawa Timur. Dari penelitian ini, diketahui bahwa Gereja Pohsarang adalah contoh arsitektur vernakular, karena bangunannya menerapkan elemen-elemen arsitektur vernakular - yang diwakili oleh budaya Jawa - dalam konteks ruang dan bentuk.
\end{abstract}

Kata kunci: budaya, gereja, vernacular

\begin{abstract}
Church is a sacred place for Catholics. Catholic faith itself did not come from Nusantara, hence the nonNusantara shape of Catholic church architecture. This becomes the main reason of doing this research, to analyze how local value affect a religious building that has a very different character, in contexts of space and form. The research is done by comparing three variables: architecture, catholic church philosophy, and Javanese building. Pohsarang church, a Catholic church located in Kediri, East Java is chosen as the case study. By doing the research it is known that Pohsarang church is actually a vernacular architecture, because it implements elements of vernacular architecture that is represented by Javanese culture both in its space and form.
\end{abstract}

Keywords: culture, church, vernacular

\section{Pendahuluan}

Di jaman modern ini, pembangunan gedung-gedung cenderung mengadopsi gaya barat, bahkan nama gedung-gedung tersebut pun, secara mentah mengambil dari negeri barat. Sedikit sekali karya arsitektur yang mengandung nilai lokal. Hal ini menggelitik ketertarikan penulis untuk membahas arsitektur yang mengandung budaya lokal. Selain untuk membuktikan bahwa bangunan yang memiliki nilai lokal indah secara estetika, tidak pernah out-of date, juga untuk mengedukasi arsitek muda dalam melestarikan budaya nusantara lewat karyanya. Gereja Pohsarang dipilih sebagai studi kasus, sebab esensinya, gereja bukanlah arsitektur yang berasal dari nusantara, mengingat iman Katolik dibawa masuk ke Indonesia lewat para misionaris (salah satunya adalah $\mathrm{Rm}$. Wolters yang merupakan penggagas pembangunan Gereja Pohsarang). Sedangkan sekilas melihat Gereja Pohsarang, bentuk dan simbol-simbolnya sungguh akrab di penglihatan kita sebagai orang Indonesia, Jawa khususnya. Hal ini menimbulkan ketertarikan penulis untuk meneliti lebih jauh tentang "kaitan" Gereja Pohsarang dengan Nusantara. 
Gereja Pohsarang adalah "hasil" dari kerjasama antara: Ir. Maclaine Pont, RM Wolters $\mathrm{CM}$, dan masyarakat setempat. Henri Maclaine Pont adalah seorang arsitek yang menggemari indigenous architecture yang dipengaruhi oleh agama dan kepercayaan. Pengetahuan lokal benar-benar membuatnya terkesan dan hal tersebut tampak dari salah satu karya masterpiece-nya yaitu Gereja Pohsarang. Bangunan ini adalah karya arsitektur yang mengandung pengetahuan lokal, terlepas dari fungsinya sebagai tempat ibadah bagi agama yang berasal dari "luar" Jawa. Hal ini juga merupakan keunggulannya, sebab menyilangkan dua hal yang sangat berbeda bukanlah sesuatu yang mudah.Gereja Pohsarang mulai dibangun di tahun 1936, yang merupakan masa sebelum Konsili Vatikan II, dimana belum ada inkulturasi liturgi. Namun, atas inisiatif dari Ir. Maclaine Pont, RM Wolters CM maka digunakanlah nilai budaya lokal dalam rancangan gereja. Hal tersebut didukung oleh hasil Konsili Vatikan II yang mendukung adanya inkulturasi liturgi dengan menyatakan bahwa inkulturasi liturgi paling mendalam bertolak dari budaya setempat (Salura, 2015, hal. 19).

Rumusan masalah dari penelitian ini adalah untuk mengetahui apakah Gereja Pohsarang merupakan contoh arsitektur vernakular, dan untuk mengetahui elemen-elemen arsitektur vernakular dalam konteks ruang dan bentuk yang diterapkan pada bangunan Gereja Pohsarang. Sedangkan tujuan penelitian adalah untuk membuktikan bahwa bangunan yang memiliki nilai lokal, indah secara estetika, tidak pernah out-of date, juga untuk mengedukasi arsitek muda dalam melestarikan budaya nusantara lewat karyanya.

\section{Variabel Penelitian}

\subsection{Teori Arsitektur}

Hal pertama yang harus dikandung oleh suatu karya arsitektur adalah unsur dalam arsitektur, antara lain: titik, garis, bidang, ruang. Jika unsur-unsur arsitektur tersebut digabungkan, maka akan membentuk suatu bentuk. Sehingga dengan adanya cukup banyak unsur, maka akan memperagam bentuk yang ada (Ching, 1999, hal. 17 - 44).

Hal kedua dalam suatu karya arsitektur adalah elemen. Elemen dalam arsitektur adalah bagian yang terdapat pada sebuah bangunan. Menurut Ching (1999, hal. 17 - 286) elemen dalam arsitektur meliputi: massa bangunan, bentuk denah bangunan, tampak bangunan, sistem struktur yang digunakan, site bangunan yang telah diolah, organisasi ruang, sirkulasi dan material bangunan. Dengan penjelasan sebagai berikut: massa bangunan adalah bangunan itu sendiri, dimana didalamnya terdapat space yang dibatasi oleh lantai, dinding, atap. Bentuk denah bangunan adalah bentuk dari denah, yang merupakan pemotongan bangunan setinggi satu meter dari atas tanah, sehingga menunjukkan pola sirkulasi bangunan. Tampak bangunan adalah visualisasi bangunan jika dilihat dari luar, untuk menjadi daya tarik bagi pengunjung sebelum memasuki bangunan. Sistem struktur yang digunakan adalah sistem penyaluran gaya yang digunakan oleh suatu bangunan. Site bangunan yang telah diolah adalah lahan bangunan yang telah diolah kembali agar lebih estetis dan sesuai dengan bangunan yang terdapat didalamnya. Organisasi ruang adalah pengaturan pola sirkulasi antar ruang, tentang apakah ruang-ruang tersebut berhubungan langsung atau tidak, dan bagaimana pencapaian masing-masing ruang. Sirkulasi adalah pola pergerakan penghuni bangunan dari satu ruang ke ruang lainnya. Material bangunan adalah bahan yang digunakan untuk membangun sebuah bangunan, utamanya adalah untuk menambah daya tarik eksterior, sehingga menarik perhatian pengunjung (Ching, 1999, hal. 17 - 286).

Hal ketiga yang terdapat dalam karya arsitektur adalah prinsip dalam arsitektur. Prinsip dalam arsitektur adalah aturan yang harus diterapkan dalam suatu karya arsitektur agar bangunan tersebut menjadi lebih bernilai, tidak hanya sebagai suatu bangunan, tetapi juga merupakan karya yang mengandung keindahan. Prinsip-prinsip dalam arsitektur meliputi: firmitas yaitu ketahanan struktur bangunan, utilitas yaitu bangunan yang fungsional 
bagi penggunanya, dan venustas yaitu keindahan yang dimiliki bangunan yang mampu menarik minat penggunanya. (Vitruvius, The Ten Books on Architecture).

Hal keempat adalah bentuk dalam arsitektur, yaitu bidang yang dibentuk oleh garis, dan dipengaruhi oleh massa bangunan, denah bangunan, tampak bangunan, sistem struktur yang digunakan, dan material bangunan (Ching, 1999, hal. 50 - 102).

Hal terakhir adalah ruang dalam arsitektur, yang merupakan gabungan bidang yang membentuk suatu bidang yang memiliki ketinggian (volume) (Ching, 1999, hal. 110).

\subsection{Vernakular}

Vernakular adalah "Bahasa" daerah, logat asli, yang berkaitan dengan bahasa rakyat atau bahasa sehari-hari (M John, Shadily, 1976, hal. 628). Bahasa adalah salah satu cara berkomunikasi. Medianya bisa bermacam-macam, antara lain arsitektur.Sehingga, vernakular merupakan segala sesuatu yang berkaitan dengan daerah asli, yang langsung melibatkan masyarakat setempat dan lingkungan sekitar (M John \& Shadily, 1976, hal. 628).

Arsitektur vernakular adalah arsitektur yang dirancang berdasarkan kebutuhan lokal, dibuat dari ketersediaan material disekitar, dan mencerminkan tradisi lokal. (https://en.wikipedia.org/wiki/Vernacular_architecture)

Dalam studi kasus ini, kasus yang hendak dianalisa adalah karya Henri Maclaine Pont, yaitu Gereja Pohsarang yang terletak di Kediri, Jawa Timur, maka diasumsikan pengetahuan lokal yang mempengaruhi adalah pengetahuan Jawa. Berikut ini, pengetahuan lokal sebagai unsur yang terdapat dalam pengertian vernakular, yaitu: candi, rumah dan wayang.

\subsubsection{Candi}

Candi-candi Budha telah membuktikan adanya cita rasa arsitektur yang tinggi sejak jaman kuno. Arsitektur Budha menampilkan simbolisme yang sangat mendalam dan menyiratkan arti tertentu yang sangat rohani. Penghayatan akan penyatuan mikro-kosmos kedalam makro-kosmos, pembebasan dari belenggu maya menuju ke penyatuan atman dan brahman menjadi pola dasar pondasi arsitektur Budha.
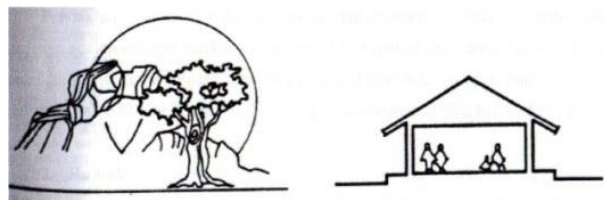

Gambar 1. Makro-kosmos dan Mikro-kosmos

(Sumber: Frick, 1997, hal. 119)

Tahap-tahap pencapaiannya meliputi: Kama Datu (dunia bawah yang kacau, masih didominasi oleh nafsu pribadi), Rupa Datu (manusia sudah mulai sadar tapi belum sepenuhnya), Arupa Datu (tahap dimana manusia telah benar-benar menuju ke kesadaran sejati).

Analogi candi adalah gunung dengan puncak, yang semakin keatas semakin meruncing, semakin polos dan hening (Mangunwijaya, 1992, hal. 122-124).

\subsubsection{Rumah}

Bagi orang Jawa, rumah adatnya adalah Rumah Joglo. Bentuk Joglo, merupakan analogi dari bentuk Gunung Mahameru, yang merupakan gunung suci, sebagai alam raya, yaitu kita semua, engkau, dan aku (Soediman, 1985, hal. 680; Gandasubrata, 1984, hal. 75). 


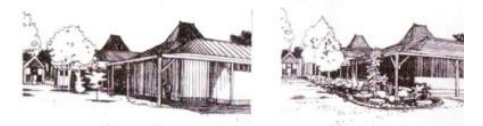

Gambar 2. Rumah Joglo yang merupakan Rumah Adat Masyarakat Jawa

(Sumber: Santosa, 2000, hal. 81)

Rumah induk pada Rumah Joglo, terdiri atas: pendopo, dalem agung, sentong, peringgitan, tratag.Sedangkan rumah tambahan terdiri atas: gandok, gadri, dapur dan pekiwan.

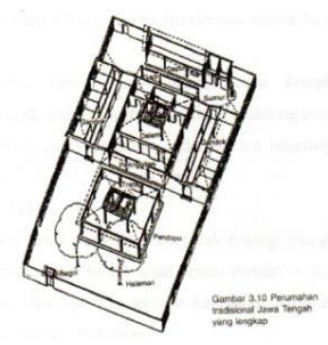

Gambar 3. Denah Lengkap Rumah Jawa yang Memperlihatkan Struktur dan Susunan Ruang Rumah Jawa

(Sumber: Frick, 1997, hal. 104)

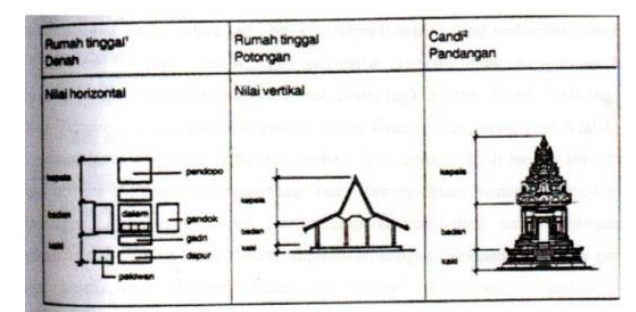

Gambar 4. Skema Pola Antropomorf pada Rumah Jawa

(Sumber: Frick, 1997, hal. 75)

Berikut ini adalah penjelasan masing-masing bagian rumah Joglo.

Pendopo adalah bagian rumah yang berfungsi sebagai tempat berkumpul orang banyak dan menerima tamu. Ruang ini bersifat terbuka. Suasana yang tercermin adalah akrab, cocok dengan fungsinya sebagai bagian penerimaan. Letak ruang ini dekat dengan regol, sehingga dapat dilihat dari luar. Hal ini dimafaatkan oleh pemiliknya sehingga pendopo cenderung dibuat berkesan megah dan berwibawa.

Dalem Agung merupakan pusat susunan ruang-ruang lain. Fungsi utamanya sebagai ruang keluarga yang bersifat pribadi. Suasana didalamnya tenang dan berwibawa. Hal ini didukung oleh penataan vastu purusha mandala suci, suatu persegi empat yang dibagi menjadi sembilan persegi kecil. Dalem terdiri atas tiga persegi tengah. Pintu dan jendelanya dipasang simetris. Keadaannya yang agak tertutup memberi kesan tenang, aman, tenteram, dan sejuk. Tiga persegi yang paling belakang membentuk sentong dan tiga persegi muka membentuk peringgitan.

Sentong merupakan tiga buah kamar yang berjajar. Pada sentong kiwo dan sentong tengen terdapat pintu berdaun dua. Kondisi udaranya cukup segar karena lubang penghawaan cukup. Ruang ini digunakan sebagai tempat tidur tuan rumah dan untuk menyimpan harta benda. Sentong tengah merupakan tempat untuk pemujaan Dewi Sri. Kondisi ruangan ini gelap tanpa pencahayaan dari luar sehingga udaranya lembab. 
Peringgitan berbentuk seperti serambi yang terdiri atas tiga persegi yang menghadap ke pendopo. Ruang ini berfungsi terutama sebagai tempat memainkan wayang. Suasana yang tercipta adalah remang-remang dan terkesan mistis.

Tratag merupakan gang diantara pendopo dan peringgitan. Gandok adalah rumahrumah disamping dalem agung. Gandok kiwo (wetan omah) untuk tidur kaum laki-laki dan gandok tengen (kulon omah) untuk kaum perempuan. Biasanya terdapat halaman pribadi antara dalem agung dan gandok. Suasana yang terjadi adalah tidak formal dan santai.

Gadri atau ruang makan terletak di belakang sentong dalem agung. Untuk menuju gadri bisa melalui pintu sentong kiwo atau sentong tengen, bisa juga lewat halaman-halaman diantara dalem agung dan gandok. Gadri bersifat semi terbuka, dan bentuknya seperti emper. Suasananya santai dan akrab, perasaan nyaman karena dindingnya terbuka dan hembusan angin bisa dirasakan.

Dapur dan Pekiwan berfungsi sebagai bagian pelayanan terletak paling belakang. Terutama kamar mandi dan kamar kecil dahulu dianggap sebegai tempat kotor, maka diletakkan sejauh mungkin di pojok belakang. Di dekat dapur dan kamar mandi terletak juga sumur.

(Sumber: Frick, 1997, hal. 86-88)

\subsubsection{Wayang}

Selain gunung, pohon juga merupakan pusat dunia, dan pusat kosmis, yang sering digambarkan dengan gunungan atau kekayon dalam pertunjukkan wayang kulit. Inilah sebabnya, banyak pohon besar yang dikeramatkan oleh masyarakat setempat. Selain itu, juga dimanfaatkan sebagai tempat semadi, mengheningkan cipta untuk merasakan kesatuan antara makro-kosmos, mikro-kosmos, antara ciptaan dan Sang Pencipta.

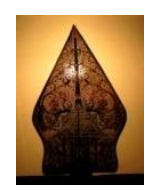

Gambar 5.Pohon sebagai Pusat Kosmis yang Digambarkan dengan Gunungan

(Sumber:http://carlos170691.deviantart.com/art/The-Courtesy-of-Wayang-Kulit-101988945)

\subsection{Gereja}

Gereja adalah tempat berkumpulnya sejumlah umat untuk melakukan suatu kegiatan keagamaan. Dalam hal ini, karena Gereja Pohsarang adalah Gereja Katolik, maka mengikuti liturgi Roma yang memang dapat diterima dimana-mana, Karena sifatnya yang sederhana, praktis, membawa ketenangan hati, pengendalian diri, daya pikat, dan kelayakannya (M.R. Francis, ibid, hal. 57)

Membangun sebuah gereja, tentunya bukan sekedar mendirikan dinding dan memberinya atap, tetapi juga menggunakan pendasaran dari beberapa aspek, yang terdiri atas: aspek teologis, aspek spiritual, aspek personal-komunal, dan aspek liturgis. Aspek teologis, terdiri atas: pengalaman akan misteri Allah, suasana sakral, simbol-simbol kelahiran Allah yang terungkap, dan rahmat Allah yang menyentuh (I.H. Dalmais, 1992, vol.1, hal. 230). Aspek spiritual, terdiri atas: sabda yang diwartakan, perjamuan Kristus yang dirayakan, membagikan rahmat Allah. Dengan penjelasan sebagai berikut: sabda yang diwartakan, mengacu pada misteri inkarnasi Kristus, sabda yang menjadi daging atau sabda yang menghidupi gereja (Tata Ruang Ibadat dalam SBL 7). Aspek personal-komunal, terdiri atas: umat yang berhimpun, pribadi yang berdoa, dan hidup dalam pelayanan (Tata Ruang Ibadat dalam SBL 7). Aspek liturgis, terdiri atas: keindahan keagungan kesahajaan, tata ruang yang serasi, seni musik dan seni dekorasi, dan benda-benda liturgi (Tata Ruang Ibadat dalam SBL 7).Pengertian liturgi menurut Konsili Vatikan ke 2, adalah perayaan misteri karya 
keselamatan Allah dalam Kristus, yang dilaksanakan oleh Yesus Kristus, Sang Imam Agung, bersama Gereja-Nya di dalam ikatan Roh Kudus (Martasudjita, 2011).

\section{Metode Penelitian dan Kajian Teori}

Penelitian ini adalah penelitian kepustakaan, karena sebagian besar data didapat dari dokumen, literatur, dan catatan yang pernah dilakukan orang lain. Untuk bisa mencari jawaban dari masalah yang ada, maka digunakan variabel dengan bangunan sebagai karya arsitektur dan Filosofi Jawa sebagai pengetahuan lokal.

Untuk mendukung proses analisa ini, maka teknik pengumpulan data yang digunakan adalah: tinjauan pustaka, pengamatan lapangan, wawancara, pencarian data dari internet.

Tinjauan pustaka yaitu penelitian yang dilakukan dengan cara membaca buku-buku, literatur, dan karya-karya ilmiah yang berhubungan dengan penelitian ini, guna mendapatkan dasar teori sebagai bahan pembahasan. Tinjauan tersebut meliputi: Budijanto, A, 1994, Gereja Pohsarang sebagai Bangunan Ibadat menurut Budaya Jawa. Disini dijelaskan tentang Gereja Pohsarang - sebagai hasil desain dari Ir. Henri Maclaine Pont - yang merupakan hasil akulturasi yang sangat harmonis antara budaya Jawa yang merupakan kebudayaan asli dalam negeri, dengan filosofi Kristiani yang berasal dari pengaruh kebudayaan Barat. Hadiwikarta, I, 1999, Pohsarang Tempo Doeloe dan di Tahun 2000. Disini dijelaskan tentang lokasi, proses pembuatan, proses renovasi, dan penggunaan Gereja Pohsarang oleh penduduk setempat di masa kini. Jessup, Helen, I, 1982, Four Dutch Buildings in Indonesia IV: Henri Maclaine Pont's Church, Pohsarang Orientations Vol 13 No 12, December, hal. 24 - 32. Disini dijelaskan tentang akulturasi antara arsitektur Jawa dengan filosofi Kristiani yang merupakan pengaruh Barat pada Gereja Pohsarang.

Pengamatan lapangan yaitu pengumpulan data yang dilakukan secara langsung pada objek penelitian. Dalam rangka mendapatkan data yang dibutuhkan, antara lain: lokasi, arsitek, akulturasi kebudayaan Jawa dan filosofi Kristiani yang mendasari, proses pembuatan, penggunaannya di masa-masa awal, renovasi, penggunaannya di masa sekarang, interior, dan gambar-gambar Gereja Pohsarang, maka dilakukan pengamatan langsung di lapangan terhadap Gereja Pohsarang.

Wawancara yaitu pengumpulan data yang berupa wawancara langsung dengan pihak yang bersangkutan, yaitu bapak Ign. Hartoko, yang bekerja sebagai petugas di Gereja Pohsarang.

Pencarian data dari internet yaitu pengumpulan data dengan cara search, browse, dan download lewat internet. Pencarian data juga dilakukan melalui internet. Dari sini didapatkan beberapa pengertian tentang arsitektur vernakular yang menjadi acuan dalam menganalisa Gereja Pohsarang.

\section{Diskusi Penelitian Gereja Pohsarang sebagai Karya Arsitektur Vernakular dalam Analisa Ruang dan Bentuk Ditinjau dari Elemen-elemen Arsitekturnya}

\subsection{Bentuk}

Gereja Pohsarang terletak di Jawa, sehingga diasumsikan pengetahuan lokal yang mempengaruhinya adalah pengetahuan Jawa. Namun, terdapat beberapa penyesuaian terhadap fungsi bangunan yaitu sebagai sebuah gereja, sehingga filosofi dan pengetahuan Jawa yang digunakan, disesuaikan dengan filosofi Kristiani yang "wajib" dikandung oleh sebuah bangunan gereja.

\subsubsection{Bangunan utama}

Salah satu pengetahuan lokal yang mempengaruhi bentuk bangunan utama adalah Gunung Meru. Bentuk Gunung Meru ini dipilih berdasarkan pertimbangan tertentu, 
yaitukarena Gunung Meru merupakan "pusat" dan merupakan tempat yang "tinggi", sedangkan masyarakat Jawa di jaman lampau menganggap bahwa semakin tinggi letak kita berpijak dan semakin mendekati pusat kita berada, semakin dekat kita dengan Sang Pencipta. Hal ini mengakibatkan dalam tradisi Jawa, bentuk ini dianggap sebagai bentuk yang suci (Jessup, hal. 54-55).

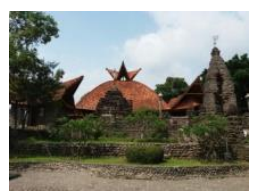

Gambar 6. Bentuk Gunung Meru yang Diterapkan pada Atap Gereja Pohsarang (Sumber: Dokumen pribadi)

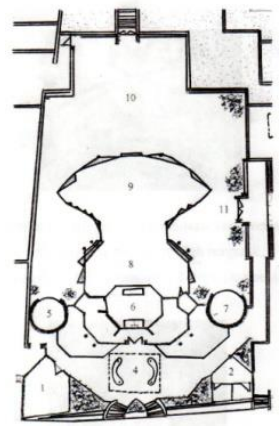

Gambar 7. Denah Lantai yang Menunjukkan Ruang-ruang pada Gereja Pohsarang

(Sumber: Keuskupan Surabaya)

Pada Rumah Jawa, ruang no.8 pada gambar denah diatas, disebut sebagai Dalem Agung yang merupakan pusat susunan ruang-ruang lain, dan bersifat pribadi, tenang, dan berwibawa. Oleh karena itu, dalam denah Gereja Pohsarang ruangan tersebut difungsikan sebagai pusat liturgi.

Kerangka kubah dibuat dari papan dan disusun berlapis-lapis dengan mur baut sebagai pengikat agar melengkung, elastis, dan mudah bergerak. Rangkaian kawat baja yang mirip sarang laba-laba sebagai tempat sandaran dan tempat bergantung genteng-genteng tersebut (Sumalyo, hal. 14).

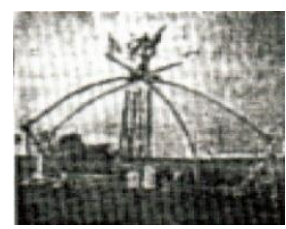

Gambar 8. Rangka Atap Asli Gereja Pohsarang Sebelum Direnovasi yang Menunjukkan Bentuk Lengkung, Elastis dan Mudah Bergerak

(Sumber: Hadiwikarta, 1999. Pohsarang Tempo Doeloe dan di Tahun 2000)

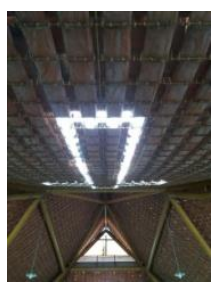

Gambar 9. Atap Gereja Pohsarang Setelah Direnovasi, Menunjukkan Rangkaian Kawat Baja sebagai Tempat Bergantung Genteng-genteng

(Sumber: Dokumen pribadi) 
Jika diamati lebih lanjut, bangunan utama, juga mirip sebuah tenda menurut Maclaine Pont, hal ini disebabkan karena esensi arsitektur Jawa adalah tenda. Bentuk tenda - yang merupakan bentuk "tempat tinggal" yang paling sederhana - telah dikenal lama oleh masyarakat di jaman lampaujauh sebelum mereka hidup menetap, dan mengenal "rumah tinggal permanen: terlebih dengan bentukan yang hampir menyerupai setengah lingkaran yang dianggap sebagai bentukan suci, bentuk tenda dianggap dapat mewakili nilai filosofi "suci" ruang pada bangunan utama. Sekaligus, dalam Bahasa Latin, tenda disebut sebagai tabernaculum, yang juga merujuk pada tempat penyimpanan Sakramen Maha Kudus (Mahatmanto, 2001, lap D-5).

\subsubsection{Atap}

Pada bangunan Jawa, usuk diletakkan rebah, tidak berdiri, sehingga diperoleh bentukan yang melendut kebawah. Dengan mempergunakan gambar balok yang dipasang tegak dan rebah, yang sama-sama diberi pembebanan merata, Maclaine Pont memperlihatkan bahwa balok yang dipasang rebah akan memiliki gaya tarik dan tekan disisi atas dan bawah lebih besar. Hanya saja dalam aplikasinya di Gereja Pohsarang, Maclaine Pont menggantinya dengan menggunakan kawat sebagai kabel penggantung. Digunakan kawat sebagai kabel penggantung, sebab kawat juga memiliki sifat lendut jika diberi beban, sehingga pada prinsipnya sama dengan balok yang dipasang rebah. Ini merupakan pengetahuan Jawa asli yang tidak terdapat di pengetahuan arsitektur manapun juga (Mahatmanto, 2001, lamp F-22).

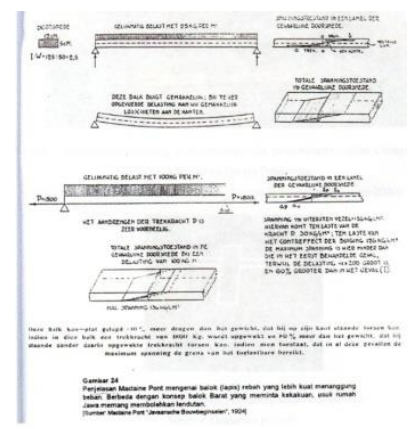

Gambar 10. Gambar sketsa usuk rebah dan skema pembebanannya, yang menjadi acuan bagi masyarakat Jawa di masa lampau dalam mendesain atap sebuah bangunan

(Sumber: Mahatmanto, 2001, lamp F-22)

Celah cahaya (hampir seperti skylight) bagi orang Jawa merupakan Dalem Ageng Proboyekso yaitu bangunan sakral yang bersifat Kejawen dimana terdapat cahaya didalamnya. Namun bagi Pohsarang, merupakan simbol dari Yesus yang digambarkan sebagai cahaya (Yohanes 14:6).

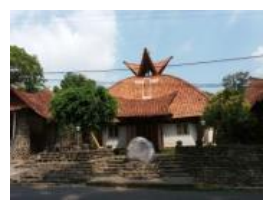

Gambar 11. Celah Cahaya pada Atap Gereja Pohsarang yang Melambangkan Yesus sebagai Cahaya (Sumber: Dokumen pribadi)

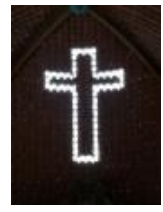

Gambar 12. Celah Cahaya dari Dalam Bangunan

(Sumber: Dokumen pribadi) 


\subsubsection{Soko Guru}

Konstruksi rumah tradisional Jawa pada umumnya menempatkan tiang utama (soko guru) sebagai bagian terpenting dari konstruksinya. Berbagai bentuk rumah tradisional Jawa, baik yang berbentuk Joglo, Limasan, Kampung, Masjid, maupun Tajug, pada umumnya memiliki empat buah pilar yang dianggap sebagai penyangga dan kekuatan utama sebuah bangunan (Mangunwijaya, 1992, hal. 304-311).

Pada Gereja Pohsarang, keempat soko guru tersebut tidak berbentuk pilar tunggal seperti pada rumah-rumah tradisional Jawa, melainkan pilar segitiga atau pilar berbentuk huruf A. Keempat soko guru melambangkan bahwa iman jemaat didasarkan pada iman para Rasul. Empat garis lengkung dan dua kaki pada masing-masing soko guru merupakan lambang dari "Keduabelas Rasul". Keduabelas garis utama itu menyatukan jaringan kawat baja yang diikat atau disatukan oleh ikatan pita cinta, yakni Kristus yang tersalib (De Katholieke Gids, 1936, hal. 332; Jessup, hal. 65).

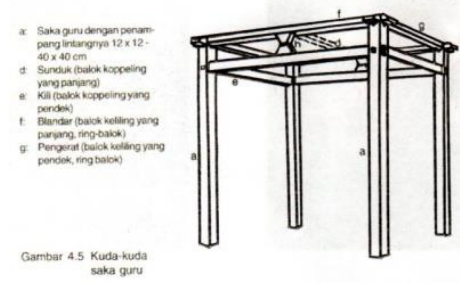

Gambar 13. Konstruksi Soko Guru sebagai Empat Kolom Utama pada Rumah Tradisional Jawa (Sumber: Dokumen pribadi)
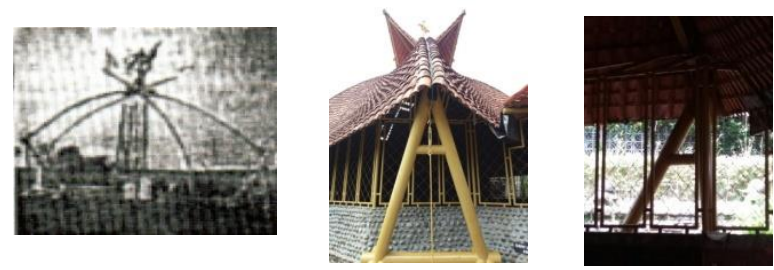

Gambar 14, 15, dan 16. Soko Guru pada Gereja Pohsarang Terhubung Langsung pada Empat Busur Utama pada Atap

(Sumber: Hadiwikarta, 1999, Pohsarang Tempo Doeloe dan di Tahun 2000dan dokumen pribadi)

\subsubsection{Menara batu}

Menara batu yang terdapat di halaman yang dalam budaya Jawa diasumsikan sebagai Lingga. Pada Gereja Pohsarang, Menara batu yang ada berupa lonceng Hendricus. Seperti lonceng-lonceng lainnya, menara lonceng ini berfungsi sebagai penanda jika misa telah dimulai.

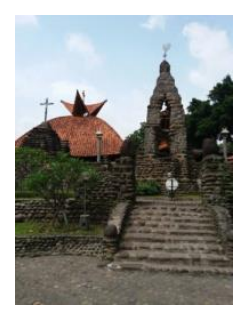

Gambar 17. Tampak depan Gereja Pohsarang menunjukkan adanya menara batu pada bagian depan, yang menghantar umat masuk ke dalam gereja

(Sumber: Dokumen pribadi) 


\subsection{Ruang}

Ruang-ruang yang terdapat pada Gereja Pohsarang, memiliki fungsi rohani yang telah disesuaikan dengan fungsi ruang yang terdapat pada pengetahuan Jawa. Maclaine Pont benarbenar memahami bahwa rasa "asing" terhadap gereja yang merupakan pengaruh Barat yang dimiliki oleh penduduk hanya dapat dihilangkan dengan menerapkan fungsi ruang dalam pengetahuan Jawa pada Gereja Pohsarang. Fungsi ruang pada suatu bangunan, cenderung lebih terasa dibandingkan bentuk, oleh sebab itu Maclaine Pont total menerapkannya pada Gereja Pohsarang.

Dalam pengetahuan Jawa dikenal beberapa bagian rumah yang terpenting, yaitu:

1. Dalem agung $\rightarrow$ Bangunan utama (garis E)

2. Pendopo $\rightarrow$ Bahtera Noeh (garis C)

3. Gapura utama $\rightarrow$ Gapura Roh Kudus (garis A)

4. Pelataran $\rightarrow$ Halaman tempat jalan salib (garis $B$ )

5. Tratag $\rightarrow$ Area antara Bahtera Noeh dan Balai Utama (garis D)

6. Gadri $\rightarrow$ Panti Imam (Garis F)

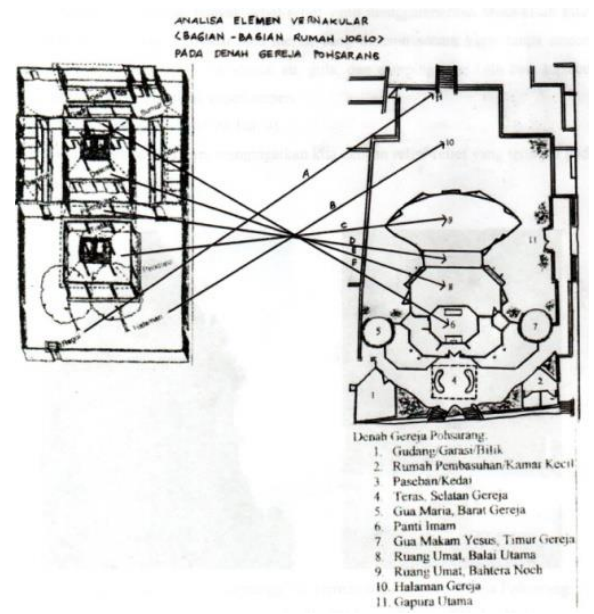

Gambar 18. Analisa Elemen-elemen Vernakular yang merupakan Bagian dari Rumah Joglo pada Gereja Pohsarang

(Sumber: Frick, 1997, hal. 104 dan Keuskupan Surabaya)

\subsubsection{Bangunan utama}

Ruang terpenting dalam bangunan Jawa adalah Dalem Agung. Dalam bangunan ini yang merepresentasikan Dalem Agung adalah Altar, dimana didalamnya terdapat banyak simbol iman, yang memiliki banyak kemiripan dengan simbol Jawa (Budijanto, 1994).

Disini juga terdapat banyak relief-relief yang menggambarkan kisah-kisah alkitab suci. Relief ini terbuat dari batu bata merah yang disusun secara kuno tanpa semen, digosok hingga halus dengan campuran air, gula, dan gamping agar batu bata tersebut saling melekat walaupun tidak diberi semen. Relief dari batu bata ini mengingatkan kita dengan relief-relief yang terdapat pada candi di Jawa Timur (Hadiwikarta, 1999, hal. 9).
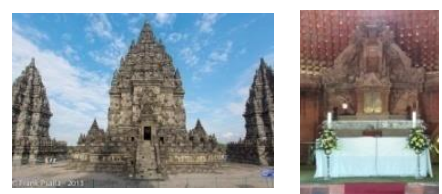

Gambar 19 dan 20. Bentukan Candi yang Turut Mempengaruhi Elemen Interior pada Gereja Pohsarang (Sumber: http://www.frankpsaila.com/?p=6268dan dokumen pribadi) 


\subsubsection{Bahtera Noeh}

Bahtera Noeh berfungsi sebagai sebuah teras terbuka yang diperuntukkan bagi para katekumen (De Katholieke Gids, 1936, page 332-449). Dalam rumah Jawa, Bahtera Noeh inilah yang disebut sebagai pendopo, yaitu sebuah tempat yang berfungsi untuk menerima tamu untuk sesrawungan (bersosialisasi) dengan masyarakat. Bentukan yang mirip pelana kuda tersebut diasumsikan sebagai Bahtera Noeh. Pada awalnya Bahtera Noeh ini digunakan sebagai tempat penyambutan bagi para katekumen, yaitu mereka yang baru mempelajari agama Katolik, tetapi seiring bertambahnya jumlah orang Katolik, tempat ini menjadi menyatu dengan Kubah Utama, sehingga tidak ada lagi perbedaan antara mereka yang baru dan yang telah lama menganut agama Katolik. Inilah mengapa tempat ini disebut sebagai tempat guyub rukun.

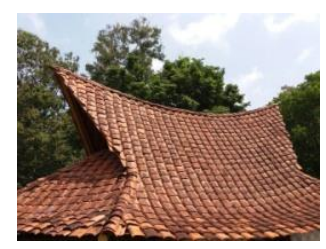

Gambar 21. Bahtera Noeh pada Gereja Pohsarang Dikenal sebagai Pendopo pada Rumah Joglo

(Sumber: Dokumen pribadi)

\subsubsection{Gapura utama}

Secara umum gapura utama pada Gereja Pohsarang membagi bangunan menjadi dua bagian besar, yaitu Ndalem dan Njaba. Sedangkan pada pengetahuan Candi Budha, membagi bangunan menjadi dua tahap utama, yaitu dunia dan nirwana. Sedangkan tahap diantara keduanya merupakan tahap peralihan atau transisi.

Pembagian tingkatan kehidupan berdasarkan agama Budha, yaitu: Kamadhatu yaitu tahap duniawi, diwakili oleh halaman biasa (sekarang halaman parkir) sama tingginya dengan rumah penduduk pada umumnya yang diasumsikan sebagai tingkat duniawi (Kemalawati, 2015, hal.82).

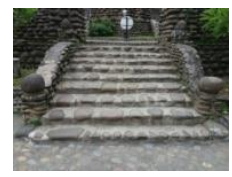

Gambar 22. Gapura pertama yang membatasi halaman terluar Gereja Pohsarang ke tingkat berikutnya, yaitu tingkat dimana manusia sudah mulai hidup di jalan Tuhan

(Sumber: Dokumen pribadi)

Rupadhatu yaitu tahap transisi dari duniawi ke nirwana (kesempurnaan), menunjukkan hidup rohani yang lebih tinggi yang dilambangkan dengan gapura gereja (Kemalawati, 2015, hal.82).

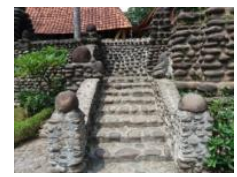

Gambar 23. Gapura berikutnya yang membatasi kehidupan manusia antara kefanaannya dengan kehidupannya yang mulai suci

(Sumber: Dokumen pribadi) 
Arupadhatu yaitu tahap nirwana (kesempurnaan dan kesucian), merupakan tahap rohani dimana manusia berjumpa dengan Allah (Kemalawati, 2015, hal.82)

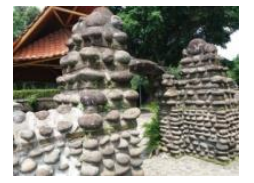

Gambar 24. Gapura akhir yang melambangkan manusia yang akan memasuki tingkat tersuci dalam hidupnya

(Sumber: Dokumen pribadi)

\subsubsection{Pelataran}

Karena pada pengetahuan Jawa yang termasuk wilayah rumah adalah semua yang berada didalam batas pagar, maka pelataran Gereja Pohsarang yang dipagari oleh tembok batu juga merupakan "ruang".Disekeliling tembok yang memagari Gereja Pohsarang, terdapat hiasan perjalanan salib Tuhan Yesus. Dimulai dari bangunan utama bagian dalam, kemudian keluar lewat pintu Barat dan langkah demi langkah perjalanan salib itu dimulai, sehingga puncaknya pada gua bagian Timur gereja. Di pelataran inilah tempat berlangsungnya jalan salib bagi umat. Filosofi tempat berlangsungnya jalan salib ini mengambil pengetahuan lokal dari Candi Borobudur, yaitu pertama-tama merenungkan perjalanan sang Budha dari tingkat yang paling dasar atau Kamadhatu hingga tingkat nirwana atau Arupadhatu sebagai puncak kesempurnaan.

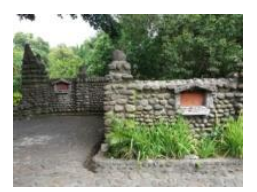

Gambar 25. Pelataran Gereja Pohsarang dibatasi oleh pagar batu di sekelilingnya, dan difungsikan sebagai tempat untuk jalan salib

(Sumber: Dokumen pribadi)

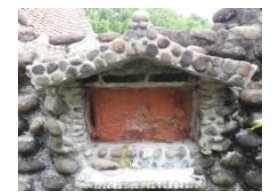

Gambar 26. Relief yang terdapat di Sekeliling Pagar Batu sebagai Tempat untuk Jalan Salib (Sumber: Dokumen pribadi)

\section{Kesimpulan}

Dari analisa Gereja Pohsarang, terbukti bahwa sebagai tempat beribadah, Gereja Pohsarang memiliki nilai lebih dibandingkan dengan gereja lainnya, sebab Gereja Pohsarang menggunakan pengetahuan Jawa sebagai konsep dasar bangunannya. Hal ini dapat dilihat dari analisa ruang dan bentuk yang didalamnya terdapat penerapan beberapa pengetahuan lokal - dalam hal ini diwakili oleh pengetahuan Jawa - yang merupakan elemen-elemen arsitektur vernakular. 


\section{Daftar Pustaka}

Ching, Francis DK. (1999). Arsitektur: Bentuk, Ruang dan Susunannya. Jakarta.

De Katholieke Gids. (1936).

Frick, Heinz. (1997). Pola Struktural dan Teknik Bangunan di Indonesia. Yogyakarta.

Gandasubrata, G. W. (1984). Arsitektur, Suatu Profesi Esoteris? Dalam: Regionalisme dan Arsitektur (kumpulan artikel). Media IAI.

Hadiwikarta, I. (1999). Pohsarang Tempo Doeloe dan di Tahun 2000.

Jessup, Helen. (1982). Four Dutch Buildings in Indonesia IV: Henri's Maclaine Pont's Church, Pohsarang Orientations vol. 13 no.12.

Kemalawati, Agoestin. (2015).Estetika Bentuk dan Makna Simbol pada Elemen Interior Gereja Puhsarang Kediri.Tesis $S 2$ Program Magister, Institut Seni Indonesia. Yogyakarta.

Mahatmanto: 2001, Representasi dalam Historiografi Arsitektur Kolonial di Indonesia. Tesis $S 2$ Program Magister.

Mangunwijaya, Y. B. (1992). Wastu Citra. Gramedia. Jakarta.

Martasudjita, E, Pr. (2011). Liturgi Pengantar untuk Studi dan Praksis Liturgi.Kanisius. Yogyakarta

M John, Echols; Shadily, Hasan. (1976). Kamus Inggris - Indonesia. PT. Gramedia. Jakarta.

Salura, Purnama; Fauzy, Bachtiar; Trisno, Rudy. (2015). Relasi Liturgi dengan Ekspresi Bentuk Sakral Arsitektur Gereja Katolik. Lembaga Penelitian dan Pengabdian kepada Masyarakat. Universitas Katolik Parahyangan. Bandung.

Soediman. (1985). Makna dan Fungsi Candi Ditinjau dari Sudut Pandang Keagamaan, dalam: Bahasa Sastra Budaya. Gadjah Mada University Press. Yogyakarta.

Sumalyo, Yulianto. (1993). Arsitektur Kolonial Belanda di Indonesia. Gajah Mada University Press. Yogyakarta.

Susanto, Suryadi Jo. (1984). Dinamika Perkembangan Arsitektur Jaman Prakolonial di Pulau Jawa, dalam: Regionalisme dan Arsitektur (kumpulan artikel). Media IAI.

Tata Ruang Ibadat dIm SBL 7.

Vitruvius, The Ten Books on Architecture.

http://carlos170691.deviantart.com/art/The-Courtesy-of-Wayang-Kulit-101988945

https://en.wikipedia.org/wiki/Vernacular_architecture

http://www.frankpsaila.com/?p=6268 